James L. Wardell and Edward R.T. Tiekink*

\title{
Crystal structure of 2-((2,8-bis(trifluoromethyl) quinolin-4-yl)(hydroxy)methyl)piperidin-1-ium trifluoroacetate, $\left[\mathrm{C}_{17} \mathrm{H}_{17} \mathrm{~F}_{6} \mathrm{~N}_{2} \mathrm{O}\right]\left[\mathrm{C}_{2} \mathrm{~F}_{3} \mathrm{O}_{2}\right]$
}

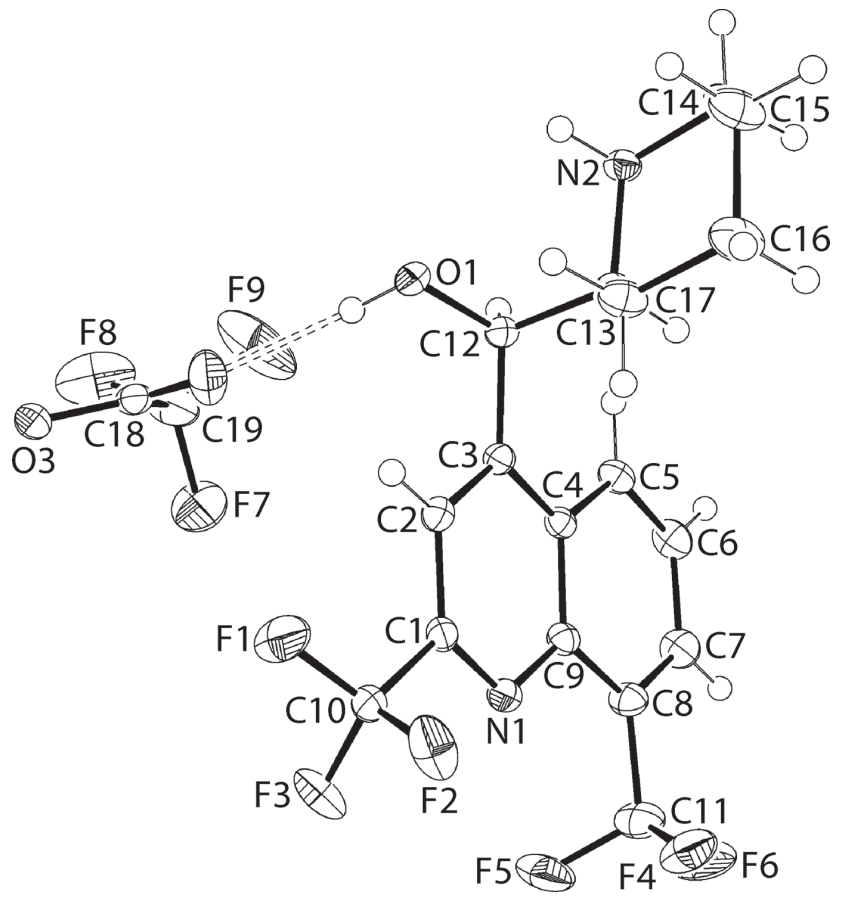

https://doi.org/10.1515/ncrs-2019-0037

Received January 13, 2019; accepted February 1, 2019; available online March 16, 2019

\begin{abstract}
$\left[\mathrm{C}_{17} \mathrm{H}_{17} \mathrm{~F}_{6} \mathrm{~N}_{2} \mathrm{O}\right]\left[\mathrm{C}_{2} \mathrm{~F}_{3} \mathrm{O}_{2}\right]$, triclinic, $P \overline{1}$ (no. 2), $a=7.9873(1) \AA$, $b=11.0534(2) \AA, \quad c=13.2380(3) \AA, \quad \alpha=105.617(1)^{\circ}$, $\beta=102.189(1)^{\circ}, \quad \gamma=106.075(1)^{\circ} . \quad V=1028.76(3) \AA^{3}, \quad Z=2$, $R_{\mathrm{gt}}(F)=0.0403, w R_{\mathrm{ref}}\left(F^{2}\right)=0.1086, T=120(2) \mathrm{K}$.
\end{abstract}

CCDC no.: 1895037

The title crystal structure is shown in the figure. Tables 1 and 2 contain details on crystal structure and measurement

\footnotetext{
*Corresponding author: Edward R.T. Tiekink, Research Centre for Crystalline Materials, School of Science and Technology, Sunway University, Bandar Sunway 47500, Selangor Darul Ehsan, Malaysia, e-mail: edwardt@sunway.edu.my

James L. Wardell: Oswaldo Cruz, Instituto de Tecnologia em Fármacos-Far Manguinhos, Rio de Janeiro 21041-250, RJ, Brazil; and Department of Chemistry, University of Aberdeen, Old Aberdeen AB24 3UE, Scotland
}

Table 1: Data collection and handling.

\begin{tabular}{ll}
\hline Crystal: & Colourless slab \\
Size: & $0.44 \times 0.26 \times 0.18 \mathrm{~mm}$ \\
Wavelength: & Mo $K \alpha$ radiation $(0.71073 \AA ̊)$ \\
$\mu:$ & $0.16 \mathrm{~mm}^{-1}$ \\
Diffractometer, scan mode: & Bruker-Nonius Roper, $\varphi$ and $\omega$ \\
$\theta_{\text {max }}$, completeness: & $27.5^{\circ},>99 \%$ \\
$N\left(h k l_{\text {measured }}, N(h k l)_{\text {unique }}, R_{\text {int }}:\right.$ & $21617,4704,0.029$ \\
Criterion for $I_{\text {obs }}, N(h k l)_{\text {gt }}:$ & $I_{\text {obs }}>2 \sigma\left(I_{\text {obs }}\right), 4151$ \\
$N(\text { param })_{\text {refined }}:$ & 307 \\
Programs: & SHELX [1-3], WinGX/ORTEP [4], \\
& COLLECT [5] and DENZO [6] \\
\hline
\end{tabular}

conditions and a list of the atoms including atomic coordinates and displacement parameters.

\section{Source of material}

Solutions of mefloquine ( $0.38 \mathrm{~g}, 1 \mathrm{mmol})$ in ethanol $(10 \mathrm{~mL})$ and trifluoroacetic acid $(0.13 \mathrm{~g}, 1.3 \mathrm{mmol})$ in ethanol $(10 \mathrm{~mL})$ were mixed and refluxed for $20 \mathrm{~min}$. On leaving the open reaction mixture at room temperature, colourless crystals were collected after 4 days. M.pt: $503-505$ K. ${ }^{1} \mathrm{H}$ NMR $(400 \mathrm{MHz}$, $\mathrm{d}_{6}$-DMSO): $\delta: 1.18-1.32$ (2H, m), 1.57-1.80 (4H, m), 3.00-3.10 $(1 \mathrm{H}, \mathrm{m}), 3.30-3.38(1 \mathrm{H}, \mathrm{br}, \mathrm{d}), 3.47-3.67(1 \mathrm{H}, \mathrm{br}, \mathrm{d}), 5.96(1 \mathrm{H}, \mathrm{s})$, $6.23(1 \mathrm{H}, \mathrm{br}, \mathrm{s}), 7.10(1 \mathrm{H}, \mathrm{s}), 7.94(1 \mathrm{H}, \mathrm{t}, \mathrm{J}=8.0 \mathrm{~Hz}), 8.14(1 \mathrm{H}, \mathrm{s})$, $8.33(1 \mathrm{H}, \mathrm{d}, \mathrm{J}=8.0 \mathrm{~Hz}), 8.75(1 \mathrm{H}, \mathrm{d}, \mathrm{J}=8.0 \mathrm{~Hz}) \mathrm{ppm} .{ }^{13} \mathrm{C} \mathrm{NMR}$, $\mathrm{d}_{6}$-DMSO): $\delta: 21.38,21.38,21.79,44.71,59.18,68.08,115.68$, 117.24 (q, J $\left.\mathrm{J}_{\mathrm{C}, \mathrm{F}}=296 \mathrm{~Hz}\right), 121.38\left(\mathrm{q}, \mathrm{J}_{\mathrm{C}, \mathrm{F}}=274 \mathrm{~Hz}\right), 123.81$ (q, $\mathrm{J}_{\mathrm{C}, \mathrm{F}}=272 \mathrm{~Hz}$ ), 126.59, 127.55 (q, JC,F $\left.=29.4 \mathrm{~Hz}\right), 128.31,128.91$, 129.86 (q, JC,F $=4.7 \mathrm{~Hz}$ ), 143.05, $147.03\left(\mathrm{q}, \mathrm{J}_{\mathrm{C}, \mathrm{F}}=34 \mathrm{~Hz}\right), 151.25$, 159.59 (q, JC,F $=32 \mathrm{~Hz})$ ppm. ${ }^{19} \mathrm{~F}$ NMR (d $\mathrm{d}_{6}$-DMSO): $\delta:-59.2$, $-67.0,-74.1 \mathrm{ppm}$.

\section{Experimental details}

The $\mathrm{C}$-bound $\mathrm{H}$ atoms were geometrically placed $(\mathrm{C}-$ $\mathrm{H}=0.95-1.00 \AA$ A and refined as riding with $U_{\text {iso }}(\mathrm{H})=1.2-$ $1.5 U_{\text {eq }}(\mathrm{C})$. The $\mathrm{O}-$ and $\mathrm{N}$-bound $\mathrm{H}$ atoms were located in a difference Fourier map and were refined with distance restraints of $\mathrm{O}-\mathrm{H}=0.84 \pm 0.01$ and $\mathrm{N}-\mathrm{H}=0.88 \pm 0.01 \AA$, respectively, and with $U_{\text {iso }}(\mathrm{H})$ set to $1.5 U_{\text {equiv }}(\mathrm{O})$ and $1.2 U_{\text {equiv }}(\mathrm{N})$, respectively. 
Table 2: Fractional atomic coordinates and isotropic or equivalent isotropic displacement parameters $\left(\AA^{2}\right)$.

\begin{tabular}{|c|c|c|c|c|}
\hline Atom & $x$ & $y$ & $z$ & $U_{\text {iso }} * / U_{\text {eq }}$ \\
\hline F1 & $0.02951(15)$ & $0.37548(13)$ & $0.38214(8)$ & 04 \\
\hline $\mathrm{F} 2$ & 24872(13) & 52419(9) & 52189(9) & $0385(2)$ \\
\hline F3 & $0.07811(13)$ & $0.35051(10)$ & $0.53895(9)$ & $.0361(2)$ \\
\hline $\mathrm{F} 4$ & $0.68301(14)$ & $0.41825(10)$ & $0.73814(8)$ & $0.0408(3)$ \\
\hline F5 & $0.46179(15)$ & $0.24409(12)$ & $0.72416(8)$ & $0.0423(3)$ \\
\hline F6 & $0.74099(17)$ & $0.25665(13)$ & $0.78058(8)$ & 21(3) \\
\hline 01 & $0.27515(13)$ & $0.17013(11)$ & $0.11193(8)$ & $0.0239(2)$ \\
\hline $\mathrm{H} 10$ & $0.1761(18)$ & $0.1277(18)$ & $0.1191(16)$ & $0.036^{*}$ \\
\hline N1 & 0.39 & 6(11) & $65(9)$ & $0.0181(2)$ \\
\hline N2 & $52889(15)$ & $0.20936(11)$ & $80(9)$ & $85(2)$ \\
\hline $\mathrm{H} 1 \mathrm{~N}$ & $0.646(2)$ & $0.1342(12)$ & $0.0828(14)$ & $0.022^{*}$ \\
\hline $\mathrm{H} 2 \mathrm{~N}$ & $0.5280(16)$ & $0.1840(16)$ & $0.0269(11)$ & $0.022^{*}$ \\
\hline C1 & $0.2 \varepsilon$ & $6(12)$ & $3(10)$ & $0.0171(2)$ \\
\hline $\mathrm{C} 2$ & 7) & 0.278 & (10) & $.0179(2)$ \\
\hline $\mathrm{H} 2$ & 0.2188 & 0.2974 & 2774 & 0.021 * \\
\hline C3 & $0.40643(17)$ & $0.20954(12)$ & $0.30800(10)$ & $0161(2)$ \\
\hline $\mathrm{C} 4$ & 0.51 & (12) & (10) & $58(2)$ \\
\hline $\mathrm{C} 5$ & 0.627 & $0.10427(13)$ & $0.37625(11)$ & $96(3)$ \\
\hline H5 & 0.6313 & 0.0656 & 0.3039 & $0.024^{*}$ \\
\hline C6 & (2) & 7(14) & $279(12)$ & $0241(3)$ \\
\hline H6 & & 0.0321 & 0.4498 & $.029^{\star}$ \\
\hline $\mathrm{C} 7$ & 2(2) & $0.14432(15)$ & $0.57128(12)$ & $0.0250(3)$ \\
\hline H7 & 63 & 0.1329 & 0.6309 & $0.030^{*}$ \\
\hline $\mathrm{C} 8$ & 9) & 783(14) & (11) & 17(3) \\
\hline C9 & & $54(12)$ & & $68(2)$ \\
\hline C10 & 8) & 13) & (11) & $4(3)$ \\
\hline C11 & 5(2) & $66(17)$ & (12) & $0.0311(3)$ \\
\hline $\mathrm{C} 12$ & $0.42225(17)$ & $0.16880(13)$ & $0.19225(10)$ & $0.0175(2)$ \\
\hline $\mathrm{H} 12$ & 2 & 68 & 715 & 0.021 * \\
\hline 13 & 17) & 0.2690 & 18944(10) & $.0170(2)$ \\
\hline $\mathrm{H} 13$ & 0.7034 & 0.2787 & 0.2510 & 0.020 * \\
\hline C14 & 2) & 15) & $226(13)$ & $74(3)$ \\
\hline $14 \mathrm{~A}$ & 7 & 54 & 127 & $.033^{*}$ \\
\hline H14B & 41 & 92 & 61 & $.033^{*}$ \\
\hline C15 & $.7754(2)$ & $488(16)$ & $.07357(14)$ & $0326(3)$ \\
\hline $\mathrm{H} 15 \mathrm{~A}$ & 0.6672 & 0.4251 & 0.0150 & $0.039^{*}$ \\
\hline H15B & 9 & 35 & 548 & 0.039 * \\
\hline C16 & $0.7578(2)$ & $0.49892(15)$ & $0.18635(13)$ & $0.0314(3)$ \\
\hline $\mathrm{H} 16 \mathrm{~A}$ & & 0.5876 & 0.1929 & 0.038 * \\
\hline H16B & & & 0.2449 & $0.038^{*}$ \\
\hline $\mathrm{C} 17$ & 58 & $0.40794(13)$ & $0090(12)$ & $.0242(3)$ \\
\hline $\mathrm{H} 17 \mathrm{~A}$ & 0.5790 & 0.4497 & 0.2746 & $0.029^{*}$ \\
\hline H17B & 0.4776 & 988 & 0.1448 & 0.029 * \\
\hline F7 & $0.08877(16)$ & 720(14) & 094(9) & $27(3)$ \\
\hline F8 & $-0.2559(2)$ & $-0.25218(11)$ & $0.08871(10)$ & $0.0584(4)$ \\
\hline F9 & $0.0247(2)$ & $-0.13334(18)$ & $0.11646(14)$ & $0.0802(5)$ \\
\hline 02 & $-0.06241(14)$ & $0.08467(11)$ & $0.13035(10)$ & $0.0345(3)$ \\
\hline 03 & $-0.35082(13)$ & $-0.03455(10)$ & $0.10914(8)$ & $0.0235(2)$ \\
\hline C18 & $-0.18437(19)$ & $-0.01618(14)$ & $0.12451(10)$ & $0.0213(3)$ \\
\hline C19 & $-0.1253(3)$ & $-0.13127(19)$ & $0.14389(14)$ & $0.0367(4)$ \\
\hline
\end{tabular}

\section{Comment}

While originally developed as anti-malarial agents, derivatives of mefloquine continue to be pharmacologically relevant [7]. These studies are augmented by crystallographic investigations which are motivated by reasons more than the confirmation of molecular structure. Thus, two out of approximately 30 crystal structures of mefloquine derivatives [8] exhibit kryptoracemic behaviour [9]. The two unusual examples were isolated during attempts at chiral resolution of racemic mefloquine (which has two chiral centres) with different carboxylic acids. In the crystal of the first example, two mefloquinium cations are related across a noncrystallographic centre of inversion, with the charge balance being provided by a pair of crystallographically independent and chiral 3,3,3-trifluoro-2-methoxy-2-phenylpropanoate anions [10]. In the second example, it was proven not necessary to have chiral carboxylate counter-ions to induce kryptoracemic behaviour. This structure arises as a result of incomplete substitution of chloride in the original salt by 4-fluorobenzenesulfonate [11]. Here, the asymmetric unit comprises a pair of pseudo-enantiomeric mefloquinium cations with the charge balance being provided by equal numbers of chloride and 4-fluorobenzenesulfonate anions [11]. As a continuation of studies in this area $[8,10,11]$, the title salt, $\left[\mathrm{C}_{17} \mathrm{H}_{17} \mathrm{~F}_{6} \mathrm{~N}_{2} \mathrm{O}\right]\left[\mathrm{C}_{2} \mathrm{~F}_{3} \mathrm{O}_{2}\right]$, was characterised.

The molecular structures of the constituents of the title salt are shown in the figure $(50 \%$ probability displacement ellipsoids). Proof that protonation occurred during crystallisation is at least two-fold. Thus, the $\mathrm{C}-$ $\mathrm{O}$ bond lengths of the carboxylate group, i.e. C18-O2, O3 of 1.2320(18) and 1.2507(17) $\AA$, are very similar. Also, the pattern of hydrogen bonding and difference Fourier maps confirm the presence of two protons on the N2 atom of the piperidin-1-ium ring. The cation exhibits familiar characteristics: an approximate L-shape with the dihedral between the quinolinyl plane [r.m.s. deviation $=0.0385 \AA$ ] and the best plane through the piperidin-1-ium ring being 69.28(4) ${ }^{\circ}$. The hydroxyl-01 and ammonium-N2 atoms are orientated to the same side of the cation with the O1-C12-C13-N2 torsion angle of $-69.08(12)^{\circ}$ indicating a - syn-clinal relationship. This proximity enables the formation of an intramolecular ammonium- $\mathrm{N}^{+}-\mathrm{H} \cdots \mathrm{O}$ (hydroxy)

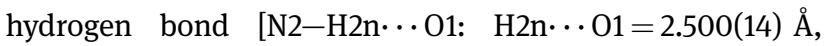
$\mathrm{N} 2 \cdots \mathrm{O} 1=2.8672(17)$ A with angle at $\left.\mathrm{H} 2 \mathrm{n}=105.8(10)^{\circ}\right]$.

The most prominent feature of the molecular packing is the formation of supramolecular chains along the $a$-axis. These are mediated by charge-assisted hydrogen bonding. Each ammonium- $\mathrm{N}^{+}-\mathrm{H}$ atom connects to a symmetry-related carboxylate-03 atom via ammonium- $\mathrm{N}^{+}-\mathrm{H} \cdots \mathrm{O}^{-}$(carboxylate) hydrogen bonds and through a centre of inversion generate eightmembered $\quad\{\cdots \mathrm{O} \cdots \mathrm{HNH}\}_{2}$ synthons $\left[\mathrm{N} 2-\mathrm{H} 1 \mathrm{n} \cdots \mathrm{O} 3^{\mathrm{i}}\right.$ : $\mathrm{H} 1 \mathrm{n} \cdots \mathrm{O} 3^{\mathrm{i}}=1.994(14) \AA, \quad \mathrm{N} 2 \cdots 03^{\mathrm{i}}=2.8580(17) \AA$ with angle at $\mathrm{H} 1 \mathrm{n}=166.5(15)^{\circ}$ and $\mathrm{N} 2-\mathrm{H} 2 \mathrm{n} \cdots \mathrm{O} 3^{\mathrm{ii}}$ : $\mathrm{H} 2 \mathrm{n} \cdots \mathrm{O} 3^{\mathrm{ii}}=2.001(15) \AA \AA \mathrm{N} 2 \cdots \mathrm{O} 3^{\mathrm{ii}}=2.7711(15) \AA$ and angle at $\mathrm{H} 2 \mathrm{n}=145.5(15)^{\circ}$; symmetry operations (i): $1-x,-y$, 
$1-z$ and (ii): $-x,-y,-z]$. The ensuing four-ion aggregates just described are connected into the supramolecular chain via charge-assisted hydroxyl-O- $-\mathrm{H}^{\cdots} \mathrm{O}^{-}$(carboxylate) hydrogen bonds [01-H1O $\cdots \mathrm{O} 2: \mathrm{H} 1 \mathrm{O} \cdots \mathrm{O} 2=1.880(16) \AA$, $01 \cdots 02=2.6856(17) \AA$ 电ith angle at $\left.\mathrm{H} 1 \mathrm{o}=160.4(19)^{\circ}\right]$.

Acknowledgements: The use of the EPSRC X-ray crystallographic service at the University of Southampton, England, and the valuable assistance of the staff there is gratefully acknowledged. JLW also acknowledges support from CNPq (Brazil).

\section{References}

1. Sheldrick, G. M.: SADABS. University of Göttingen, Germany (2007).

2. Sheldrick, G. M.: A short history of SHELX. Acta Crystallogr. A64 (2008) 112-122.

3. Sheldrick, G. M.: Crystal structure refinement with SHELXL. Acta Crystallogr. C71 (2015) 3-8.

4. Farrugia, L. J.: WinGX and ORTEP for Windows: an update. J. Appl. Crystallogr. 45 (2012) 849-854.
5. Hooft, R. W. W.: COLLECT, data collection software. Nonius BV, Delft, The Netherlands (1998).

6. Otwinowski, Z.; Minor, W.: Processing of X-ray diffraction data collected in oscillation mode. Methods Enzymol. 276 (1997) 307-326.

7. Gon calves, R. S. B.; Kaiser, C. R.; Louren co, M. C. S.; Bezerra, F. A. F. M.; de Souza, M. V. N.; Wardell, J. L.; Wardell, S. M. S. V.; Henriques, M. G.; Costa, T.: Mefloquineoxazolidine derivatives derived from mefloquine and arenecarbaldehydes: in vitro activity including against the multidrug-resistant tuberculosis strain T113. Bioorg. Med. Chem. 20 (2012) 243-248.

8. Wardell, J. L.; Jotani, M. M.; Tiekink, E. R. T.: 2-\{[2,8Bis(trifluoromethyl)quinolin-4-yl](hydroxy)methyl\}piperidin1-ium trichloroacetate: crystal structure and Hirshfeld surface analysis. Acta Crystallogr. $\mathrm{E} 74$ (2018) 1851-1856.

9. Fábián, L.; Brock, C. P.: A list of organic kryptoracemates. Acta Crystallogr. B66 (2010) 94-103.

10. Wardell, J. L.; Wardell, S. M. S. V.; Tiekink, E. R. T.: A kryptoracemic salt: 2-\{[2,8-bis(trifluoromethyl)quinolin-4-yl](hydroxy)methyl\}-piperidin-1-ium (+)-3,3,3-trifluoro-2-methoxy2-phenylpropanoate. Acta Crystallogr. E72 (2016) 872-877.

11. Jotani, M. M.; Wardell, J. L.; Tiekink, E. R. T.: Crystal structure and Hirshfeld analysis of the kryptoracemate: bis(mefloquinium) chloride $\mathrm{p}$-fluorobenzenesulphonate. $Z$. Kristallogr. 231 (2016) 247-255. 